\title{
The Tribology Behaviour of Polycarbonate Urethane (PCU) as Advance Material on Biomedic
}

\author{
Wahyu Dwi Lestari *, Ndaru Adyono \\ Department of Mechanical Engineering, Faculty of Engineering, Universitas Pembangunan Nasional \\ "Veteran" Surabaya, East Java, Indonesia
}

*Corresponding author:

E-mail:

wahyu.dwi.tm@upnjatim.ac.id

\begin{abstract}
End-stage osteoarthritis of the hip can be treated by replacing the joints using an artificial hip joint. Recent research states that polycarbonate urethane (PCU) can be used as an alternative bearing in UHMWPE material because of its better properties. This study aimed to determine the value of friction coefficient, the width of wear track, The volume of wear track, wear rate, and wear particle analysis. The method used is to test the wear of the PCU material using a pin on the disc tribometer machine. The wear test was carried out for 50,000 cycles with a loading of 500 grams and variations in speed (50 Rpm, $100 \mathrm{Rpm}, 200 \mathrm{Rpm}$ ). The test is carried out in conditions without lubrication. The results of this study showed that the average friction coefficient of $50 \mathrm{NL}, 100 \mathrm{NL}$, and 200NL PCU discs were $0.114,0.116$, and 0.127 , respectively. The width track values of the $50 \mathrm{NL}, 100 \mathrm{NL}$, and $200 \mathrm{NL}$ disc specimens were $2,679 \mathrm{~mm}, 4,168 \mathrm{~mm}$, and 5,211 $\mathrm{mm}$, respectively. The volumetric wear values of the $50 \mathrm{NL}, 100 \mathrm{NL}$, and $200 \mathrm{NL}$ disc specimens were $76,428 \mathrm{~mm}^{3}$, $355,104 \mathrm{~mm}^{3}$, and $1049,328 \mathrm{~mm}^{3}$, respectively. The wear rate specimen disc values of 50NL, $100 \mathrm{NL}$ and 200NL using the wear track calculation method were $1.352 \times 10^{-3} \mathrm{~mm}^{3} / \mathrm{Nm}, 6.283 \times 10^{-3} \mathrm{~mm}^{3} / \mathrm{Nm}$, and $1.857 \times 10^{-2} \mathrm{~mm}^{3} /$ $\mathrm{Nm}$, respectively.
\end{abstract}

Keywords: polycarbonate urethane (PCU), pin on the disc, coefficient of friction, wear rate

\section{Introduction}

Biomaterials are synthetic materials that are used to make medical devices and interact with biological systems in their use. One of the biomaterials applications is the treatment of osteoarthritis. Osteoarthritis is a disease that attacks the joints, caused by a series of processes ranging from structural disturbances, then spreading to the joints, and finally causing failure in the joint area (Nuki, 1999). One of the most common ways to treat osteoarthritis problems, especially in the hip, is to do a total hip replacement (THR) (Mellon, et al., 2013). THR is a hip replacement medical operation in the form of cutting the head and neck of the femur and removing the acetabular cartilage which is replaced by a prosthesis (Siopack \& Jergensen, 1995). In total hip replacement (THR), there are several constituent parts, including the femoral stem, femoral neck, femoral head, acetabular liner, and acetabular shell (Pruitt \& Chakravartula, 2011). There are various types of bearing pairs in artificial hip joints, including metal on metal bearings, polyethylene on metal bearings, ceramic on ceramic bearings, polyethylene on ceramic bearings, and polycarbonate urethane on metal bearings (Gabarre et al., 2014).

One of the polymers used in the manufacture of bearings in artificial hip joints in the human body is ultra-high molecular weight polyethylene (UHMWPE). This material has been used in implants in the human body since the early 1960s and remains the best standard as a polyethylene

\section{How to cite:}

Lestari, W. D., \& Adyono, N. (2020). The tribology behaviour of polycarbonate urethane (PCU) as advance material on

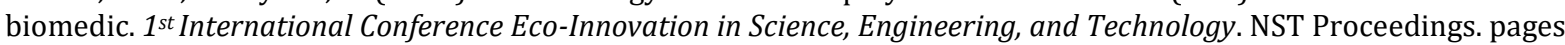
112-118. doi: 10.11594/ nstp.2020.0517 
on metal bearing material in total joint replacement (Kurtz, 2009). This cannot be separated from the nature of UHMWPE which is resistant to wear and pressure (Muratoglu, 2001).

In recent years, a type of polyurethane family, polycarbonate urethane (PCU), has been proposed as a suitable candidate to replace UHMWPE as a bearing material in orthopedic applications (Muratoglu, 2001). PCU materials show lower friction and wear rates than UHMWPE (Smith, Ash, \& Unsworth, 2000). PCU also has good biocompatibility, which is proven by having resistance and resistance to chemical testing. Besides, the mechanical properties of PCU are also of better value than UHMWPE. These advantages allow PCU material to be aligned with UHMWPE in terms of its good biocompatibility and mechanical properties. Another study conducted by (Smith, Maghsoodpour, \& Hallab, 2009) showed that PCU has the same or even better wear properties than UHMWPE due to its hydrophilic properties, and the modulus of elasticity of PCU is said to be 70 times more flexible than UHMWPE.

From some of the descriptions of the explanation above, it can be concluded that polymers, especially PCU, are a material that can support implant prosthesis tools because of the many properties of PCU which are suitable for the manufacture of implant prosthesis tools, especially bearing material. Besides, the properties of PCU are of better value than the previous bearing material, namely UHMWPE, so that it can improve the quality of prosthetic bearings. As a bearing material, an understanding of the tribology of the material must be made, especially the wear and friction coefficient of the bearing material (Cowie et al., 2019). It is necessary to analyze the number, size distribution, and volume of wear particles produced to determine the level of wear (Elsner et al., 2010). This can be done by testing using a tribometer, namely, a pin on the disc. The pin on disc tribometer is a machine that can simulate movement in the joints because the contact form on the tool is in the form of rotation (ASTM, 2000) which resembles joint motion. Also, the final result is influenced by the presence of a lubricant or without lubrication, because the results obtained will be different even in the same lubricating conditions but different lubricants are used. The purpose of this study was to determine the tribology phenomenon of PCU materials by carrying out wear testing using a pin on the disc tribometer machine. The test was carried out in dry conditions (without lubrication) with variations in the speed of $50 \mathrm{Rpm}, 100 \mathrm{Rpm}$, and $200 \mathrm{Rpm}$. The results of the test are the friction coefficient and the wear rate.

\section{Research Method}

The research begins by literature review to study matters related to research. The next step is to make a disc and pin specimen. The materials used in this study were PCU for disc specimens and SS 316L for pin specimens. Disc specimens are manufactured using compression molding, whereas pins are manufactured by turning machines. The wear test was carried out using a pin on disc tribometer engine in dry conditions (without lubrication). Each test was carried out with variations in rotational speed, namely $50 \mathrm{Rpm}, 100 \mathrm{Rpm}$, and $200 \mathrm{Rpm}$. The fixed variables in this test are the same loading value of 500 grams, and the number of cycles used is 50.000 cycles. After the wear test is carried out, the wear track geometry is measured using a surface roughness tool to determine the width, depth and volumetric area of the resulting wear track. The existing wear track geometry data is then used in calculating the wear rate according to the wear track calculation method. The flow chart of the PCU material wear testing in this study is shown in Figure 1. 

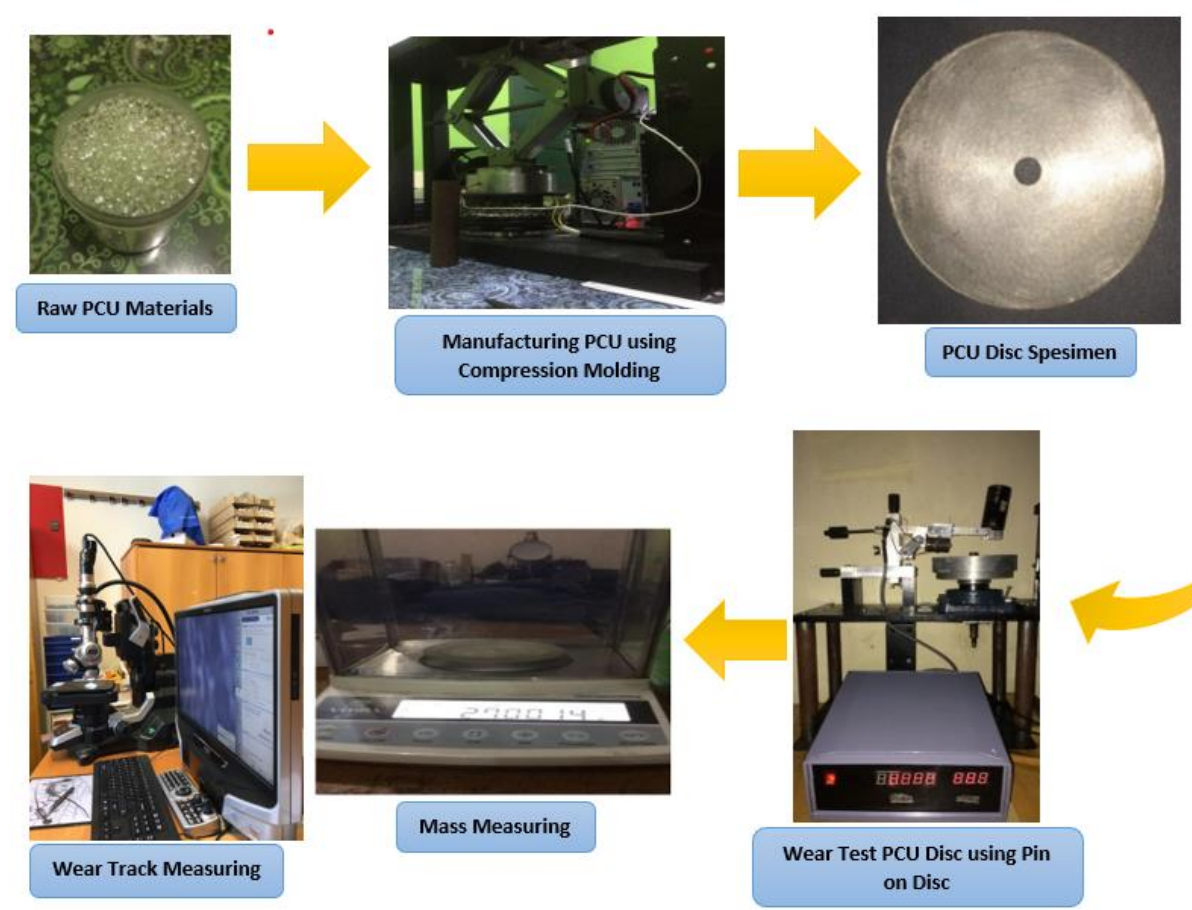

Figure 1. The flow chart of PCU material wear test using the pin on disc machine

\section{Results and Discussion}

Tribological testing is carried out to determine tribological phenomena such as friction, wear on the contact mechanism between the SS $316 \mathrm{~L}$ pin and the PCU disc. The pin on the disc test is performed in dry conditions (dry test). The test was carried out using a pin on disc tribometer. The results obtained from these tests are mass reduction after testing, friction coefficient, and wear track geometry profile of PCU disc specimens. Mass measurement in this study was conducted to determine the mass value of the disc before and after the pin on the disc, the test was carried out. This measurement was carried out because during the test there was a reduction in size and volume in the form of frictional pieces called wear particles. The results of PCU mass measurement are shown in Table 1.

Table 1. PCU disc mass measurement results

\begin{tabular}{llll}
\hline No. & Name of PCU disc & Before & After \\
\hline 1. & $50 \mathrm{NL}$ & $27,088 \mathrm{~g}$ & $27,001 \mathrm{~g}$ \\
2. & $100 \mathrm{NL}$ & $27,083 \mathrm{~g}$ & $26,691 \mathrm{~g}$ \\
3. & $200 \mathrm{NL}$ & $27,057 \mathrm{~g}$ & $25,883 \mathrm{~g}$ \\
\hline
\end{tabular}

\section{Friction coefficient}

The coefficient of friction data obtained from the three PCU disc specimens as much as 150,000 data. The data is then processed using statistical data processing software to determine the trendline of the friction coefficient value of each PCU disc. The graph that shows the results of the trendline value of the PCU disc friction coefficient can be seen in Figure 2. Based on the friction coefficient graph, it can be seen that the three PCU disc specimens show almost the same trendline 
friction coefficient. The three specimens, namely the PCU 50NL, 100NL, and 200 NL disc specimens, had a large trendline at the beginning then increased slowly to the highest point, ending with a decrease at the end of the cycle. The average value of the friction coefficient of the three PCU disc specimens was analyzed using ANOVA with a significance level of $5 \%$ in the statistical data processing software. Based on the analysis, the results showed that the 50NL specimen had an average friction coefficient of 0.114 . The $100 \mathrm{NL}$ specimen has an average friction coefficient of 0.116 . The $200 \mathrm{NL}$ specimen has an average friction coefficient of 0.127 .

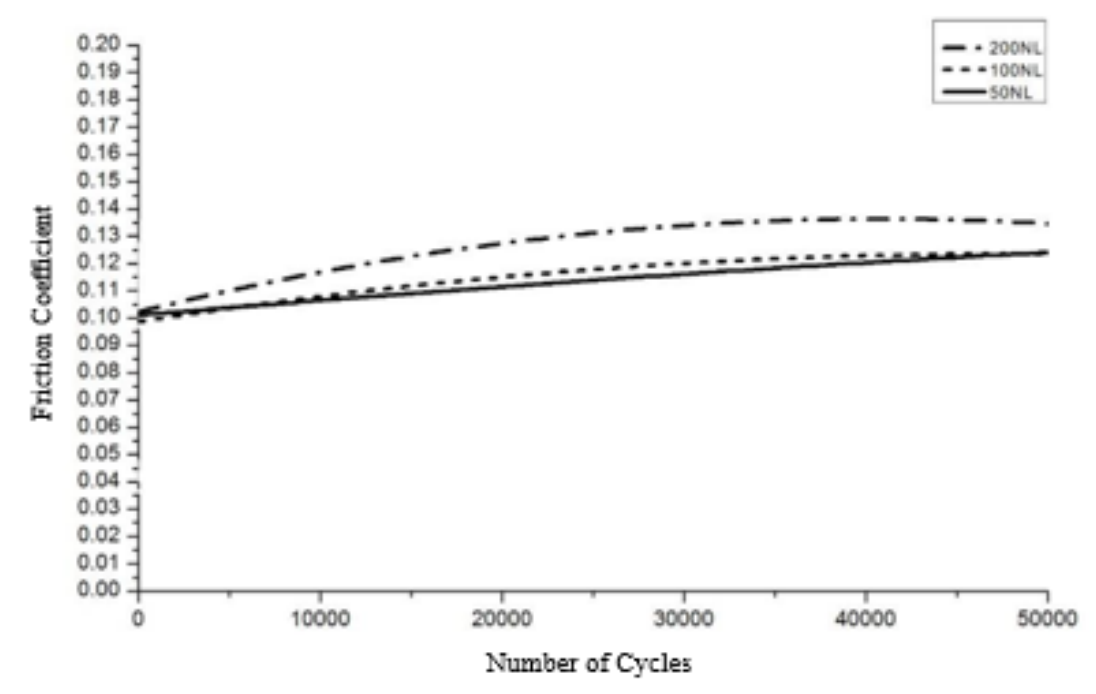

Figure 2. Graph of the friction coefficient for the three PCU disc specimens

The friction speed affects much higher than the applied pressure. The friction between the materials results in the formation of heat at high temperatures and hence increases the temperature at the friction surface of the two materials. The higher the friction speed the higher the temperature increases, and as the temperature reaches the polymer softening point, the adhesive component increases leading to a higher friction coefficient value (Unal et al., 2004). It can be concluded that the higher the rotational speed used, the higher the coefficient of friction. From the results obtained, the value of the PCU disc friction coefficient is smaller than the coefficient friction value of the UHMWPE disc for dry lubrication conditions.

\section{Wear rate}

Specimens that have been tested for the pin on disc wear are then measured for their wear profile using a Mitutoyo SJ-210 surface roughness tool. The results of measuring the wear track profile of each PCU disc specimen can be seen in Figure 3. From the predetermined pin on the disc test, several values were found that can be used to calculate the wear rate (Ka). The volumetric wear value in this method is calculated from the track wear profile. The calculation of the wear rate (Ka) can be done using equation (1). The load is given (P) is 500 grams. The value of the sliding distance on a PCU disc with a diameter can be calculated by equation (2). 


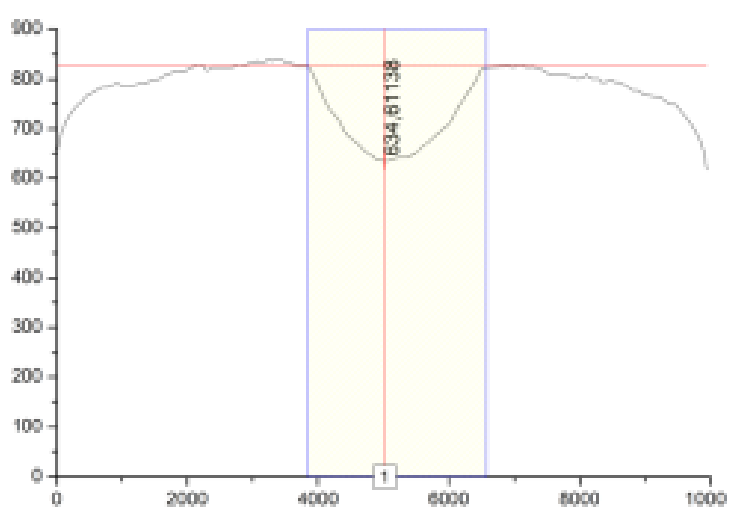

(a)

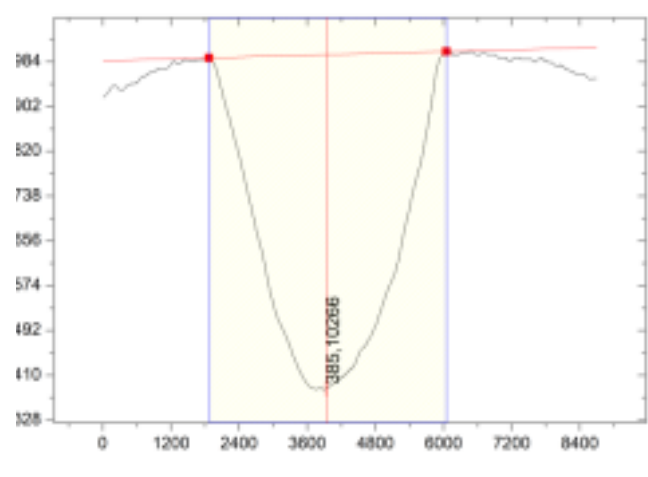

(b)

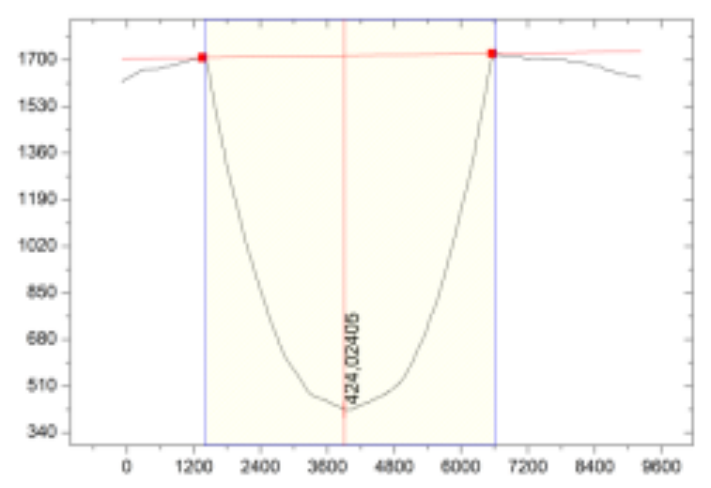

(c)

Figure 3. PCU disc specimen wear profile (a) $50 \mathrm{NL}$, (b) $100 \mathrm{NL}$, (c) $200 \mathrm{NL}$

$$
K a=\frac{V}{F n S}
$$

$\mathrm{S}=$ Circumference 1 Turn $\mathrm{x}$ Number of Cycles (2)

Where,

Radius $=0.036 \mathrm{~m}$

Circumference 1 Turn $=2 \pi R=2 \times 3.14 \times 0.036 \mathrm{~m}=0.22608 \mathrm{~m}$

Number of Cycles $=50,000$ Cycles

$$
\mathrm{V}=\mathrm{A} \times \mathrm{S}(3)
$$

Where:

$\mathrm{Ka}=$ wear rate $(\mathrm{mm} 3 / \mathrm{Nm})$

$\mathrm{V}=$ Volumetric wear $(\mathrm{mm} 3)$

$\mathrm{Fn}=$ Load given $(\mathrm{N})$

$\mathrm{S}=$ Sliding distance $(\mathrm{m})$

$A=$ cross sectional area $(\mathrm{mm} 2)$

From the results of the above calculations, the value of the sliding distance $(\mathrm{X})$ can be obtained. amounting to $11.304 \mathrm{~m}$. The method for calculating the wear rate is with calculates the volumetric wear of the PCU disc wear track. Volumetric wear can be obtained by multiplying the 
cross-sectional area of the wear track by the sliding distance for one turn. The equation used is equation (3). By using the calculation results and equation (3), the wear rate value for each PCU disc specimen can be found.

The wear rate values for the three PCU disc specimens were obtained using the volumetric wear calculation method using a wear track. In the volumetric area calculation method using the wear track, data such as track width, track depth for each specimen, volumetric area, and wear rate values are obtained. The results of these calculations are then discussed and compared with existing studies to determine the validation of the values obtained. In this study, the smallest track width value is $2.679 \mathrm{~mm}$ which is owned by the $50 \mathrm{NL}$ PCU disc specimen. This was followed by the PCU $100 \mathrm{NL}$ disc specimen with a track width of $4.168 \mathrm{~mm}$. The largest track width value is owned by the PCU 200 NL disc specimen, which is $5.211 \mathrm{~mm}$. Similar to the track width, the smallest track depth in this study is also owned by the PCU 50 NL disk specimen, which is $0.193 \mathrm{~mm}$. This was followed by a $100 \mathrm{NL}$ PCU disc specimen with a track depth of $0.612 \mathrm{~mm}$, and the largest depth was owned by a $200 \mathrm{NL}$ PCU disc specimen of $1.292 \mathrm{~mm}$.

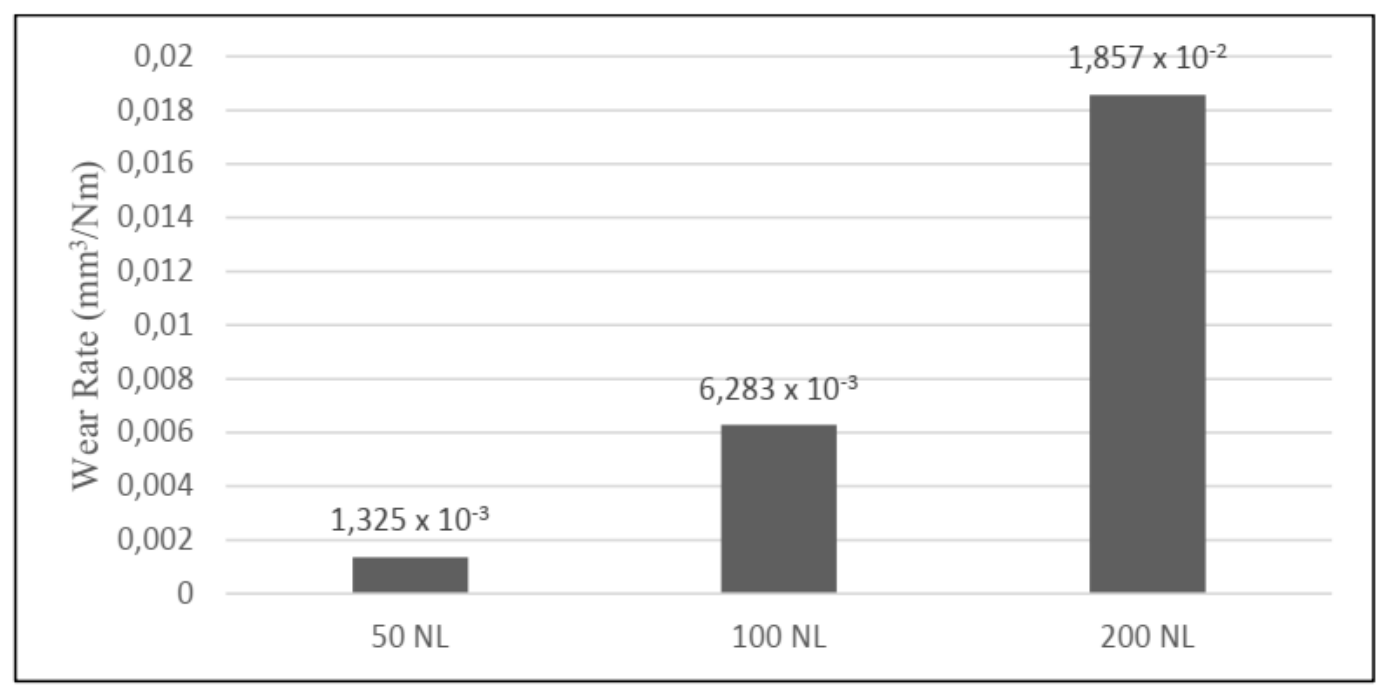

Gambar 4. The wear rate value for each PCU disc specimen

The results of the calculation of the volumetric wear value showed that the PCU 50 NL disc specimen had the smallest value, which was $76.428 \mathrm{~mm}^{3}$. Furthermore, the PCU $100 \mathrm{NL}$ disc specimen had a value of $355.104 \mathrm{~mm}^{3}$, and the largest volumetric wear value was found in the PCU $200 \mathrm{NL}$ disc specimen of $1049.328 \mathrm{~mm}^{3}$. The results of the wear rate calculation in this study are shown through a graph in Figure 4.Based on the graph, it can be seen that the 50NL disc specimen has the smallest wear rate of $1.352 \times 10^{-3} \mathrm{~mm}^{3} / \mathrm{Nm}$, followed by the $100 \mathrm{NL}$ specimen which has a wear rate of $6.283 . \times 10^{-3} \mathrm{~mm}^{3} / \mathrm{Nm}$. The highest wear rate is owned by the $200 \mathrm{NL}$ disc specimen, which has a wear rate of $1.857 \times 10^{-2} \mathrm{~mm}^{3} / \mathrm{Nm}$.

\section{Conclusion}

Based on the results of the PCU material wear test using a pin on the disc tribometer machine, the following conclusions are obtained.

1. $50 \mathrm{NL}, 100 \mathrm{NL}$, and $200 \mathrm{NL}$ specimens had an average coefficient of friction of $0.114,0.116$, and 0.127 , respectively. The value of the friction coefficient is smaller when compared with the UHMWPE friction coefficient value.

2. Disc specimen track width values of $50 \mathrm{NL}, 100 \mathrm{NL}$ and 200NL respectively 2,679 mm, 4,168 $\mathrm{mm}$ and 5,211 $\mathrm{mm}$. The volumetric wear value specimen disc $50 \mathrm{NL}, 100 \mathrm{NL}$ and 200NL respectively $76,428 \mathrm{~mm}^{3}, 355,104 \mathrm{~mm}^{3}$ and $1049,328 \mathrm{~mm}^{3}$. 
3. The wear rate of the specimen disc is $50 \mathrm{NL}, 100 \mathrm{NL}$ and $200 \mathrm{NL}$ respectively $1.352 \times 10^{-3}$ $\mathrm{mm}^{3} / \mathrm{Nm}, 6,283 \times 10^{-3} \mathrm{~mm}^{3} / \mathrm{Nm}$ and $1,857 \times 10-2 \mathrm{~mm}^{3} / \mathrm{Nm}$.

\section{Acknowledgment}

The authors thanks to Universitas Pembangunan Nasional "Veteran" Surabaya for this funding and support of this research

\section{References}

ASTM Standard. (2000). G 99 - 05 Standard test method for wear testing with a pin-on-disc apparatus. Wear, 5, 1-5

Cowie, R. M., Biscoe, A., Fisher, J., \& Jennings, L. M. (2019). Wear and friction of UHMWPE-on-PEEK OPTIMA. Journal of Mecahical Behaviour of Biomedical Materials, 89, 65-71.

Elsner, J. J., Mezape, Y., Hakshur, K., Shemesh, M., Linder-Ganz, E., Shtreling, A., \& Eliaz, N. (2010). Wear rate evaluation of a novel polycarbonate-urethane cushion form bearing for artificial hip joint. Acta Biomaterialia, 6, 4698- 4700.

Gabarre, S., Herrera, A., Mateo, J., Ibarz, E., Lobo-Escolar, A., \& Gracia, L. (2014). Study of polycarbonate-urethane/metal contact in different positions during gait cycle. BioMed Research International, 2014, 1-11.

Kurtz, S. M., (2009). The UHMWPE handbook: principles and clinical applications in total joint replacement. 2nd ed. New York: Elsevier Academic Press.

Mellon, S. J., Liddle, A. D. \& Pandit, H. (2013). Hip replacement: landmark surgery in modern medical history. Maturitas, 75(3), 221226.

Muratoglu, O. K., (2001). A novel method of cross-linking ultra-high-molecularweight polyethylene to improve wear, reduce oxidation, and retain mechanical properties. J Arthroplast, 2(16), 149-160.

Nuki, G. (1999). Osteoarthritis: a problem of joint failure. Zeitschrift fur Rheumatologie, 58(3), 142-147.

Pruitt, L. A. \& Chakravartula, A. M., (2011). Mechanics of biomaterials: fundamental principles for implant design. Cambridge: Cambridge University Press.

Siopack, J. S., \& Jergensen, H. E. (1995). Total hip arthroplasty. Decision-Making in Orthopedic and Regional Anesthesiology: A Case-Based Approach, 162, 243-249.

Smith, R. A., Maghsoodpour, A. \& Hallab, N. J., (2009). In vivo response to crosslinked polyethylene and polycarbonate-urethane particles. Journal of Biomedical Materials Research Part A, 1(93), 347-355.

Smith, S. L., Ash, H. E. \& Unsworth, A., 2000. A tribological study of UHMWPE acetabular cups and polyurethane compliant layer acetabular cups. Journal of Biomedical Materials Research, 6(53), 710-716.

Unal, H., Sen, U. \& Mimaroglu, A., 2004. Dry sliding wear characteristics of some industrial polymers. Tribology International, 37, 727732. 